\title{
Bioabsorbable osteofixation devices in craniosynostosis. Clinical experience in
} 216 cases

\author{
M.J. Muñoz-Casado; A.I. Romance* y J.I. García-Recuero*
}

Unidad de Cirugía Craneofacial (Servicio de Neurocirugía Pediátrica y Cirugía Maxilofacial*). Hospital Universitario 12 de Octubre. Madrid.

\section{Summary}

Introduction. The pursuit of bone fixation systems capable of affording appropriate stability for osteosynthesis has gone through several stages from the use of metal wires, plates, and screws to the current stage of bioabsorbable systems. In our Pediatric Neurosurgery Service and Craniofacial Surgery Unit we began employing these systems in June 1997. The object of this paper is to present a review of the bioabsorbable materials most commonly used in pediatric age, and more specifically in treating craniosynostosis, to describe the characteristics of each one of them and our experience.

Patients and methods. From June 1997 to May 2006 we implanted bioabsorbable fixation systems in $\mathbf{2 1 6}$ patients diagnosed with craniosynostosis. Age at treatment ranged between 4 and 24 months (mean age 6, 38 months). Brain computed tomography (CT) scans, and three-dimensional (3-D) reconstruction of CT scans were performed before and after treatment. An 82: 18 L-lactic acid: glycolic acid copolymer was used in 92.2\% of these cases, and a 70:30 L-lactic acid: D-lactic acid copolymer was used in the remaining $7.8 \%$ of cases. The follow-up of the patients ranged between six months and five years.

Results. There was no displacement of bioabsorbable plates or screws in any case. In one case $(0.46 \%)$, radiological imaging revealed osteolysis underneath the implant eight months after the surgical procedure. Prominences caused by the plates and screws employed were visible in two cases $(0.93 \%)$. We found fractures in the osteosynthesis mesh in two patients $(0.93 \%)$. Four patients $(1.85 \%)$ presented local inflammation. No alterations of cranial morphology secondary to inadequate stability were observed.

Conclusions. 1) Bioabsorbable fixation systems provide excellent stability during the bone "healing" period, without a higher complication rate than with other systems. 2) They help the bone grafts keep their

Recibido: 22-05-08. Aceptado: 9-07-08 remodeled shape. 3) They promote reossification by preventing the bone grafts from moving after osteosynthesis. 4) No interference with normal growth of the cranial vault has been observed.

KEY WORDS: Osteosynthesis. Bioabsorbable systems. Craniosynostosis. Rigid fixation. Polylactic. Polyglycolic.

Sistemas bioabsorbibles de fijación ósea en craneosinostosis: Experiencia clínica en 216 casos

\section{Resumen}

Introducción. La búsqueda de sistemas de fijación ósea que proporcionen la estabilidad adecuada para favorecer una osteosíntesis, ha dado lugar a diferentes etapas. Desde la utilización de hilos de alambre, placas y tornillos metálicos hasta la etapa actual en la que se utilizan sistemas bioabsorbibles. En nuestro Servicio de Neurocirugía Pediátrica y Unidad de Cirugía Craneofacial comenzamos a utilizar estos sistemas en Junio de 1997. El objetivo de este trabajo es realizar una revisión de los materiales bioabsorbibles utilizados en la edad pediátrica, concretamente en craneosinostosis, aportando información sobre las características de cada uno de ellos y nuestra experiencia.

Pacientes y métodos. Desde Junio de 1997 a Mayo de 2006, hemos utilizado sistemas de fijación bioabsobible en 216 pacientes diagnosticados de craneosinostosis. Las edades oscilaron entre 4 y 24 meses cuando se realizó el tratamiento (la edad media fue 6,38 meses). Todos los casos fueron estudiados con escáner cerebral y reconstrucción tridimensional antes y después del tratamiento. En el 92,2\% de los casos el copolímero utilizado fue el formado por los ácidos L-Láctico y Glicolico en las proporciones de $82 / 18$ y en el $7,8 \%$ restante el sistema formado por el copolímero de los ácidos L-Láctico y D-Láctico en la proporción de 70/30. El período de seguimiento ha oscilado entre 6 meses y 5 años.

Resultados. No hubo desplazamientos de placas o tornillos bioabsorbibles en ningún caso. En un caso 


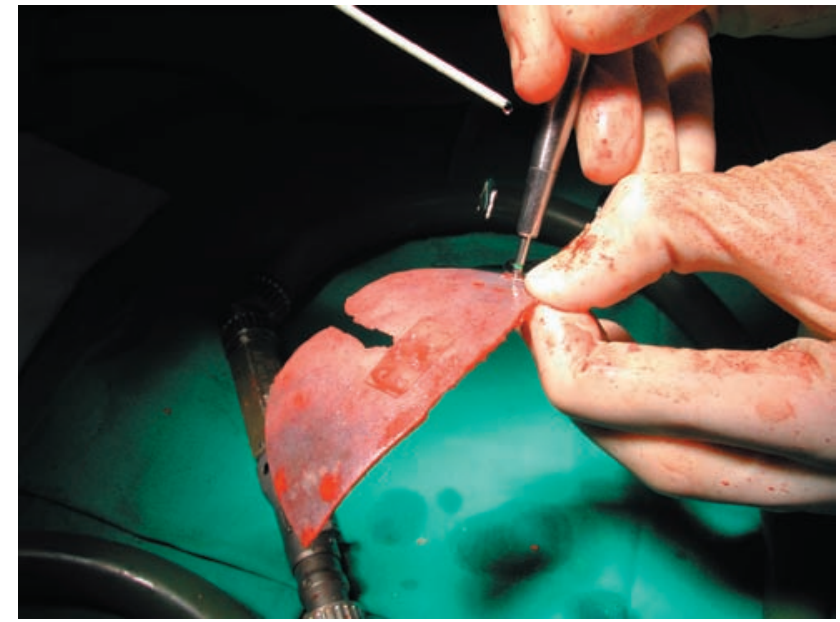

Figure1. Remodeling of both frontal bones. Intraoperative view: a) perforation. b) osteosynthesis

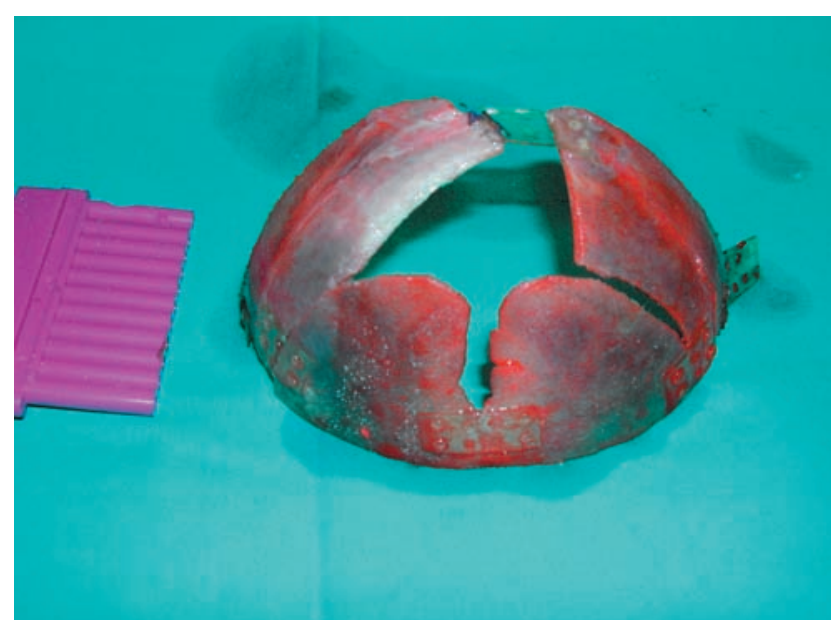

tric craniofacial surgery in $1996^{2,6,7}$. These systems afford suitable rigidity during the reossification process, thereby helping to stabilize osteotomized bone grafts in the skull, while no migration of the materials or restriction of cranial growth has been described. The first bioabsorbable system for pediatric craniofacial surgery approved in the United States was and 82:18 lactic acid: glycolic acid copolymer ${ }^{2}$. In vitro tests have shown that $70 \%$ of copolymer rigidity has been lost after six to eight weeks. In vivo histological studies have demonstrated virtually complete disappearance of the system approximately one year after implantation $^{2,9,10,13}$. The ability to manage degradation time and complete elimination have made these systems ideal for stable osteosynthesis. We have been using bioabsorbable fixation systems since June 1997. There is no doubt that during these years we have not only tested the properties of the bioabsorbables material but also the technical difficulties derived from a relatively young craniofacial surgery, difficulties which we have overcome through experience.

\section{Patients and methods}

From June 1997 to May 2006 we have used bioabsorbable fixation systems in 216 pediatric patients with the following diagnosis: 51 with unilateral coronal synostosis, 68 with metopic synostosis, 49 with sagittal synostosis, 9 with brachycephaly, and 39 with multiple synostosis. Patient age ranged from 4 to 24 months at the time of treatment (mean age 6,38 months). Brain computed tomography (CT) scan, and three-dimensional (3-D) reconstruction of CT scans were taken in all the patients before and after treatment. The antibiotic prophylaxis was the currently used in transcranial surgery. A specific prophylaxis related to the material used was not employed. During the postoperative period we perform clinical exploration and radiological studies of the skull in all cases. The postoperative follow- 


\section{Table 1}

\begin{tabular}{|lcc|}
\hline SUGICAL PROCEDURE & $\mathrm{N}^{\mathrm{o}}$ Patients & DIAGNOSIS \\
RMF-with ORA & 119 & plagiocephaly-trigonocephaly \\
RMF & 34 & scaphocephaly \\
RMF with AF & 9 & brachycephaly \\
DMHC & 63 & brachycephaly-multiple synososis-scaphocephaly \\
ORA=orbital rim advancement. RMF=Fronto-orbital remodeling; DMHC=Holocranial & dismantling. AF=Frontal advancement.
\end{tabular}

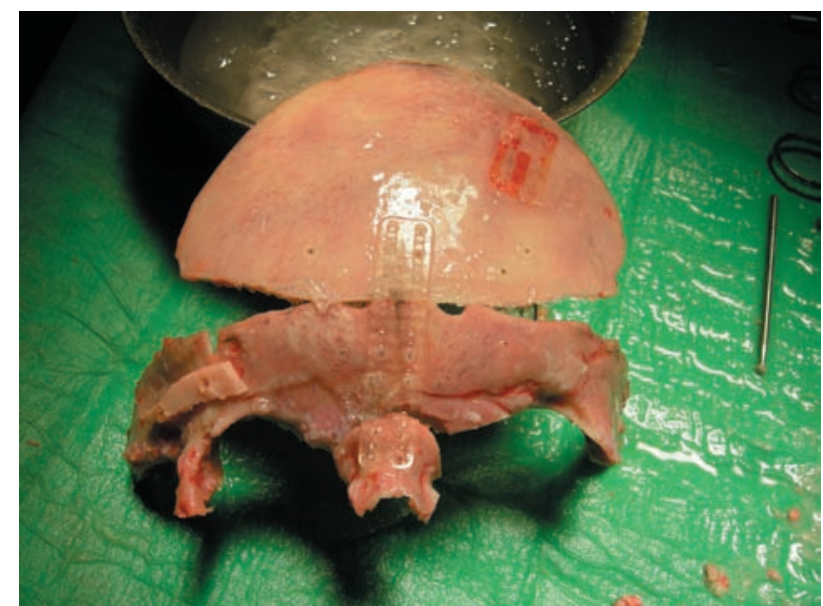

Figure 2. Fronto-orbital remodeling with bar. The forehead and fronto-orbital bar are fixated with bioabsorbable system.

up evaluated clinical signs of infection or local inflammation, visibility of plates through the skin, instability, and reoperation.

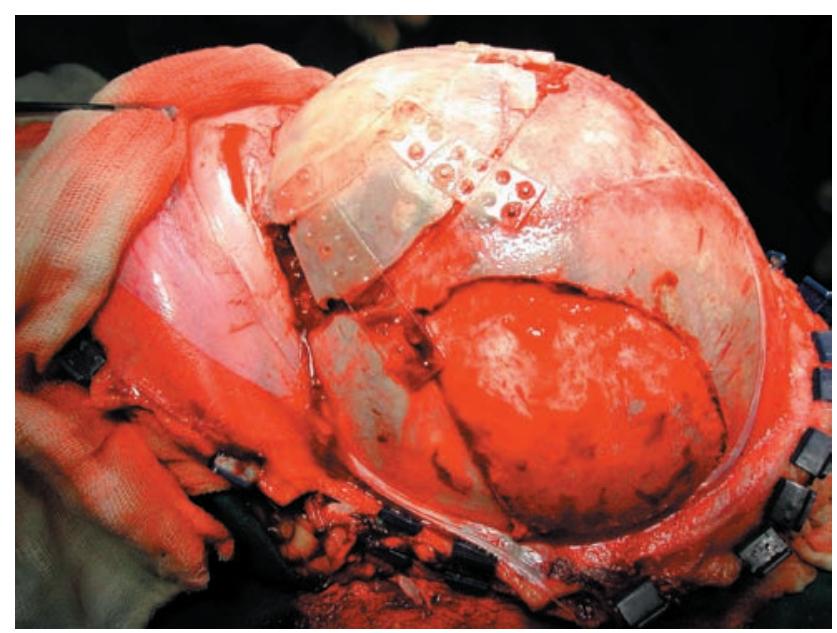

Use of bioabsorbable systems. A copolymer consisting of 82:18 L-lactic acid: glycolic acid was used in $92.2 \%$ (Lactosorb $\AA$ ) of the cases on the basis of patient age and pathology. We typically employed 50x50 mesh and $1.5 \times 5$ screws, both previously shaped and sized to the areas of the skull where they were going to be attached. The mesh was shaped by applying dry heat so that it would soften and become moldable for a short time. For the L-lactic acid: Dlactic acid copolymer, shaping was done by hand. The mesh was cut using surgical scissors and the screws with small chisels. Perforations in the bone were made perpendicular to the surface so that the screws could be inserted perpendicularly, so that they would not break (fig 1). Surgical Techniques (table I) (figures 2, 3, 4, 5, 6, 7). 1) Frontal-orbital remodelation: We have performed a bifrontal craniotomy with remodelation of the frontal bone and repositioning on the fronto- orbital bar, or transposition of a new frontal from the parietal region. 2) Holocranial dismantling: In those with deformities of the skull cavity important, the remodelation intailed a modification of the three diameters of the skull cavity. 3) Occipital remodelation: performed on

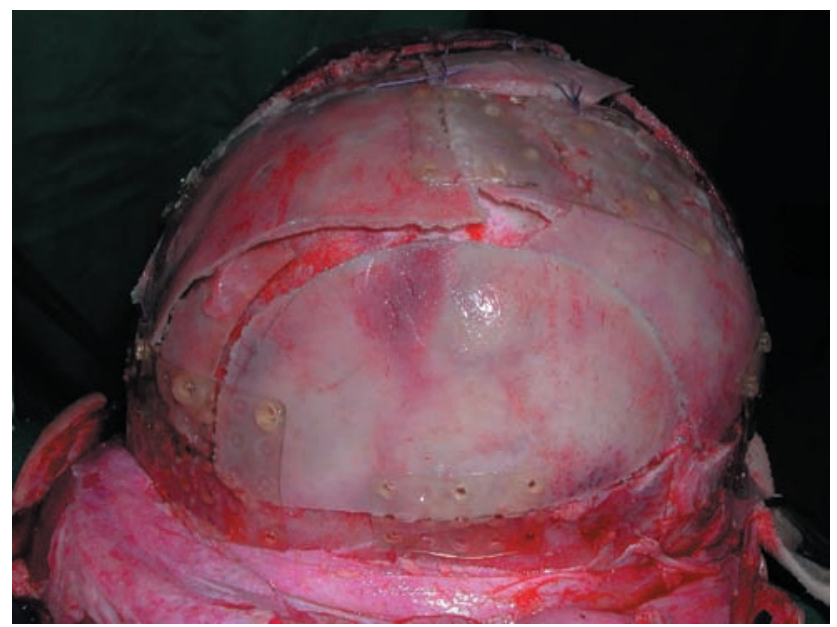

Figure 3. Fronto -orbital remodeling without bar. a) Lateral view. Transposition of a new frontal bone from the parietal region; b) Frontal view. Osteosynthesis: fronto-malar and fronto-nasal. 

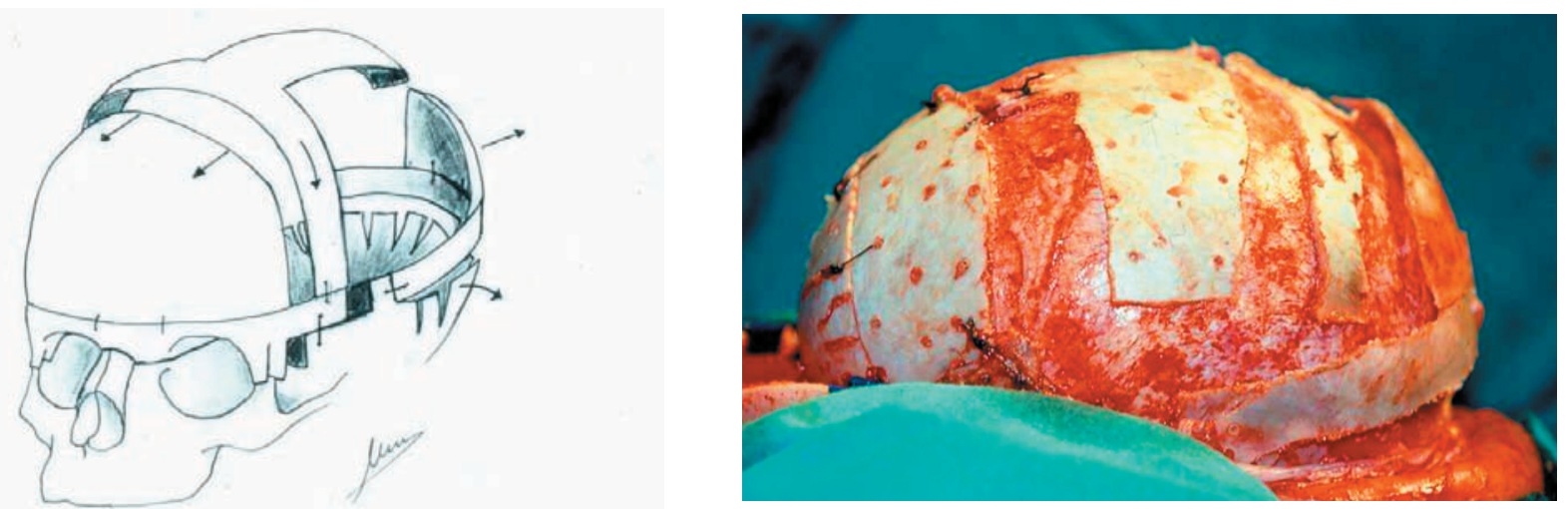

Figures 4. a) Diagrammatic representation of Holocranial dismantling. Occipital remodeling. b) Intraoperative view.

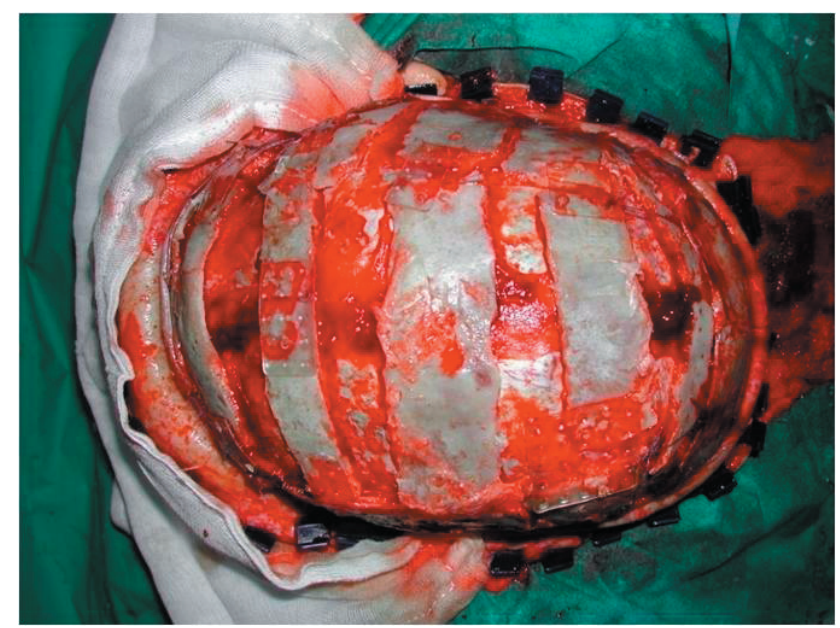

Figure 5. Scaphocephaly. Holocranial dismantling

patients who needed a complete remodelation of the skull cavity, requiring a occipital craniotomy, remodelling later the bone or rotating the hanging osseous for later fixation with osteosynthesis .

\section{Results}

Follow-up lasted from six months to five years. Clinical examination and neuroimaging showed osteosynthesis to be stable in all the cases. No displacement occurred in those cases in which frontoorbital and occipital advancement was performed. In two patients $(0.92 \%)$, diagnosed with brachycephaly and frontal plagiocephaly, frontal bone prominences were observed as a result of fracture of the osteosynthesis mesh, and additional interventions were carried out to remove the implants $\left(0,3 \%\right.$ Eppley $\left.^{5}\right)$. Mesh breakage may have been due to the mechanical traction that is necessary when suturing the coronal cutaneous incision. In four cases $(1.85 \%)$ in which $10 \times 25$ meshes were used for to perform osteosynthesis, we detected cutaneous inflammatory reaction over the are of the mesh in conjunc-

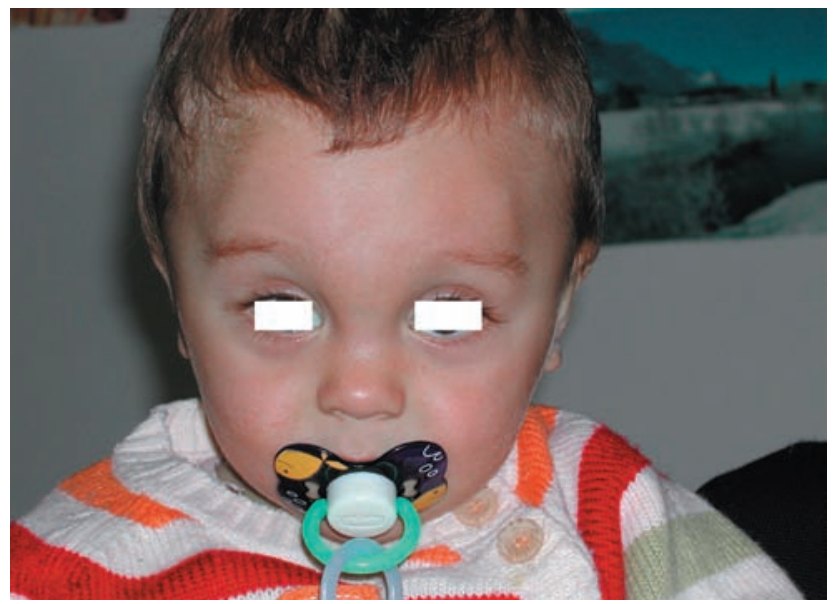

Figure 6. Patient with bilateral frontal prominences.

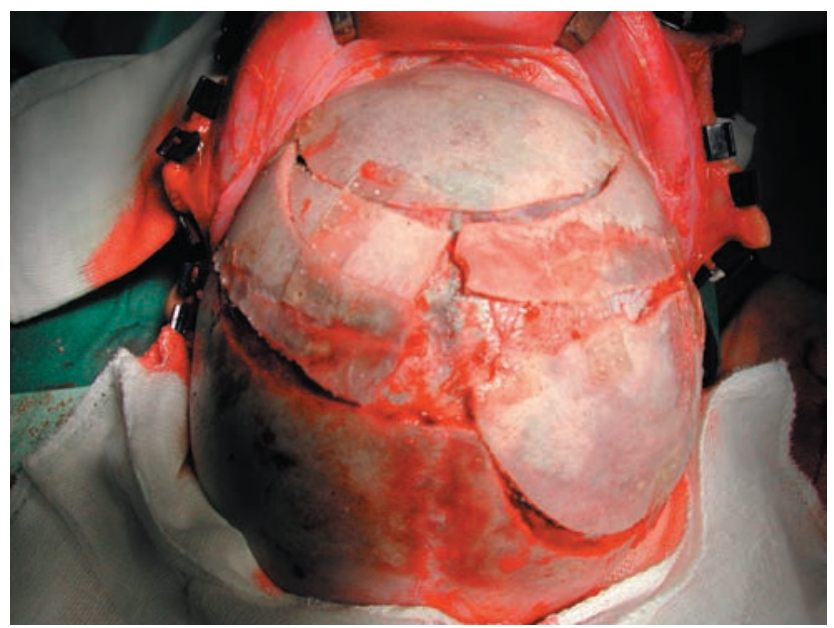

Figure 7. Intraoperative view. Frontal remodeling. Bilateral frontal prominences of patient in figure 6.

tion with rising body temperature, moderate leucocytosis, sterile blood cultures, and normal C-reactive protein levels $\left(0,7 \%\right.$, Eppley ${ }^{2,5}, 1,36 \%$ Habal $\left.^{10}\right)$. These symptoms remitted without treatment some four or five days after onset ${ }^{5}$. 
Table II

Material bioabsorbable

\begin{tabular}{lcc}
\hline \multicolumn{1}{c}{ Copolymer } & loss times strength & resortion \\
\hline $\begin{array}{l}82 \% \text { L-lactic acid and } \\
18 \% \text { glycolic acid }\end{array}$ & $70 \%$ at 8 weeks & $12-15$ months \\
\hline $\begin{array}{l}\text { Self-reinforced lactic acid } \\
\text {-glycolic acid }\end{array}$ & $6-8$ weeks & 12 months \\
\hline $\begin{array}{l}\text { Self-reinforced L-lactic acid/ } \\
\text { DL-lactic acid 70/30 }\end{array}$ & $18-36$ weeks & $2-3$ years \\
\hline Lactic acid L/DL 70:30 & $70 \%$ at 24 weeks & 2 years \\
\hline
\end{tabular}

An osteolytic lesion $(0,46 \%)$ at the level of the osteosynthesis was diagnosed radiologically in a single case eight months after the procedure. Clinically this patient had local pain and swelling which remitted spontaneously. Frontal prominences (figures 6,7) were observed in two patients $(0,92 \%)$ during the first six months $\left(1,36 \% \mathrm{Habal}^{10}\right)$. These were caused by the plates and screws employed and the need to insert the implants at an angle to achieve an anatomical curve in the frontoparietal reconstruction. Subsequent clinical and radiological evolution was satisfactory.

\section{Discussion}

Since the first operations on patients suffering from alterations in cranial morphology, techniques have evolved seeking not just normalization of the three dimensions of the cranial vault but esthetic improvement as well ${ }^{6,14}$. Craniotomies and replacing bone grafts in the desired positions calls for the implantation of osteosynthesis materials to provide adequate stability ${ }^{4,10,12}$. The initial approach to these materials involved external systems that had to remain in place for substantial periods of time, but after removal there was nothing to keep the remodeled bone from destabilizing? These materials fell out of use some years ago but have come back as osteogenic distraction systems. The second stage was sterile metallic wires, but because of the nature of the bone in very young patients, they failed to achieve proper fixation. Titanium plates and screws were the third stage. These systems, still in use today, provide rigid fixation throughout the entire ossification period. However, they restrict growth, and certain complications such as migration of the plates towards the skull cavity, sores, and prominences underneath the skin have been described ${ }^{6,7}$. Metal systems of this kind require a second intervention to remove the plates and interfere with radiological scans and certain cancer treatments. What might be regarded as the fourth but perhaps not the last stage began in 1996 with the introduction of synthetic bioabsorbable materials for craniofacial surgery.

All the systems previous to bioabsorbable systems had unwanted effects. When seeking to develop a system free from adverse factors, it helps to posit the features that would make up an ideal system ${ }^{10,12,13}$. Such systems should a) afford stability similar to that provided by titanium during the first six weeks, regarded as the reossification period; b) not compromise bone growth; c) reduce complication rates as compared to other systems; d) not interfere with radiological examinations and/or cancer treatments; e) avoid the need for reintervention to remove the fixation system components when they have finished their job; f) offer complete, programmable and natural reabsorption ${ }^{16}$.

Bioabsorbable materials, consisting of polymers made up of long chains of macromolecules, have all these ideal attributes. When all the molecules are the same, they are called homopolymers, and when the chains are formed from different types of molecules, they are called copolymers. Implant rigidity, the degradation process, and degradation time all depend on polymer type and proportions in the copolymer blend $d^{2,3,4,5,16}$. The three-dimensional organization of the polymer molecules gives rise to a crystalline structure.

Degradation takes place in two stages in all systems (table II). In the first stage, internal degradation brought about by hydrolysis leads to a predictable reduction in strength independently of plate size. This is the result of penetration of water from the tissues surrounding the implant, giving rise to micro-fragmentation and a reduction in the molecular weight or weights of the polymer or copolymer. In the second stage, surface resorption of the fragmented polymers takes place as a result of phagocytosis by macrophages. The breakdown products are metabolized to water and carbon dioxide, eliminated by respiration in the case of lactic acid and glycolic acid and excreted by the kidneys in the case of polydioxane. Implant size does 
have a bearing in this second stage, with formation of a capsule around the breakdown products. Such polymer attributes as size, molecular weight, and the degree of crystalline structure all influence degradation, along with other patient-related factors such as age, implantation site, and vascularization. Before the chains that make up crystalline polymers begin to lose their rigidity, the molecules forming the chains have to undergo a high degree of fragmentation, thereby slowing down the elimination of the bioabsorbable materials. The polymers that are currently available ${ }^{12,15,16}$ and hence are most commonly used in blending copolymers are 1) poly(L-lactic acid), 2) polyglycolic acid, and 3) polydioxane. Poly (L-lactic acid) has the highest mechanical strength of all existing polymers and thus is the one most commonly used. The loss of strength is quite slow, only $25 \%$ over the first three months, and $100 \%$ at one year. Because it is hydrophobic and highly crystalline, complete degradation does not take place until four to five years after implantation. As a result of the aforesaid chemical properties, thick plates may cause local inflammatory reactions and even sterile abscesses. At the present time copolymers of L-lactic acid and D-lactic acid are used to reduce these undesirable effects. Another polymer currently available is a derivative of polyglycolic acid. Because it is semicrystalline and degrades very quickly, accumulations of breakdown products from metabolization of this polymer outpace the body's ability to eliminate them, and this can be a source of such adverse reactions as local inflammation and sometimes osteolysis. This material is not used in its pure form. Polydioxane can cause transitory osteolytic reactions in the area around the implant. It loses $20 \%$ to $40 \%$ of its strength in six to eight weeks and degrades completely in six months.

Blending appropriate proportions of these polymers yields copolymers with known rigidity and resorption rates that can be tailored to requirements. At the present time several different copolymer blends are in use, namely, a) 82:18 L-lactic acid:glycolic acid (Lactosorb $\AA$ ), which loses $70 \%$ of its rigidity after six to eight weeks and disappears completely 12 to 15 months after implantation; b) a self-reinforcing lactic acid/glycolic acid copolymer ${ }^{11,16,17}$ (Biosorb-PDX®), which loses its rigidity after six to eight weeks and is reabsorbed in one year; c) self-reinforcing 70: 30 L-lactic acid: DL-lactic acid (Biosorb®), which gradually loses strength over a period of between 18 and 36 weeks and is completely degraded in two to three years; and d) a copolymer composed of DL-lactic acid 70:30 (providing strength), D-lactic acid (moldable), (PoliMax $\left.{ }^{\circledR}\right)$.

The choice of system to be employed depends on patient age and the condition being treated. One of the main and perhaps the most important requirements in pediatric craniofacial surgery is for fixation systems not to interfere with bone growth. Alteration of cranial morphology secon- dary to craniosynostosis is the condition most commonly treated by surgery ${ }^{5,6,7,14}$, and entails significant remodeling of the cranial vault. Achieving stability of the bone grafts has represented a challenge because of both the high degree of disassembly and the nature of the bone. The bone making up the cranial vault in these patients is quite thin, which means that the screws inserted to hold the mesh in place can be unstable in certain areas ${ }^{8}$. We have solved this problem by laying down a small piece of bone to increase bone thickness. Other solutions have entailed using bioabsorbable sutures or dispensing with mesh entirely and fixing the bone grafts in place with bioabsorbable screws. Another drawback is the visible outline of the plates frontally, which has esthetic repercussions until they degrade. This problem has been addressed by reducing plate thickness and by performing endocranial osteosynthesis procedures ${ }^{17}$. The latter procedure may pose problems by reason of potential difficulties in removing the implants should reintervention be required. Our practice when a patient has needed surgical reintervention on account of wound infection is to remove the bioabsorbable system, and we resort to endocranial placement only for esthetic reasons when implants are visible. The loss of rigidity over the course of the early weeks is a very important property of pediatric bioabsorbable materials, making them a good choice for use in patients who need enlargement of the anterior cranial fossa, for instance in brachycephaly, and use of these systems enables us to perform frontoorbital advancement while avoiding excessive, unsightly correction.

\section{Conclusions}

1. Bioabsorbable fixation systems afford excellent stability during the bone "healing" stage following surgical intervention and prevent displacement in the case of frontoorbital advancement.

2. They help the bone grafts keep their remodeled shape.

3. They promote reossification by preventing the bone grafts from moving after osteosynthesis.

4. No interference with normal growth of the cranial vault has been observed.

5. There has been no increase in morbidity.

\section{References}

1. Cutright, D.F., Hunssuck, E.E., Beasley, J.D.: Fracture reduction using a biodegradable material, polylactic acid. J Oral Surg 1971; 29-393.

2. Eppley, B.L., Sadove, A.M., Havlik, R.J.: Resorbable plate fixation in pediatric craneofacia surgery. Plast Reconstr Surg 1997; 100: 1-7.

3. Eppley, B.L., Reilly, M.: Degradation characterstic of 
PLLA-PGA bone fixation devices. J Craniofac Surg 1997; 2: 116-120.

4. Eppley, B.L: Potencial for guided bone regenetation and bone graft fixation with resorbable memebranes in pediatric craniofacial surgery. J Craniofac Surg 1997;2: 127-128.

5. Eppley, BL., Morales, L., Word, R., et al.: Resorbable PLLA-PGA and screw fixation in Pediatric Craniofacial Surgery: Clinical Experience in 1883 patiens. Plast Reconstr Surg 2004; 4: 850-856.

6. Esparza, J., Muñoz, M.J., Hinojosa, J., Romance, A., Muñoz, A., Mendez, D: The operative treatment of the anterior synostosis plagiocephaly. Analysis of 45 cases. Childs Nerv Syst 1998; 14: 448-454.

7. Fearon, J.A., Munro, I.R., Chir, B., Bruce, A.D.: Observations on the use of rigid fixation for craniofacial deformities in infants and young children. Plast Reconstr Surg 1995; 95: 634-637.

8. Godstein, J.A., Quershy, F.A., Choen, A.R.: Early experience with biodegradable fixation for congenital pediatric craneofacial surgery. J Craniofac Surg 1997; 2 : 110-115.

9. Habal, M.B.: Absorbable, invisible, and flexibleplating system for the craniofacial skeleton. J Craniofac Surg 1997; 2: 121-126.

10. Habal, M.B., Pietrzak, W.S.: Key points in the fixation of the craniofacial skeleton with absorbable biomaterial. J Craniofac Surg 1999; 6: 491-499.

11. Hears, P.E., Sailer, H.F: Biodegradable self-reinforced poly L/DL lactide plates and screws in bimaxillary orthognathic surgery: short term skeletal stability and material related failures. J Cranio-maxilofacial Surg 1998; 26: 363-372.

12. Kumar, A., Staffenberg, A., Petronio, A., Wood, J.: Bioabsorbibles Plate and Screws in Pediatrc Craniofacial Surgery: A revision of 22 cases . J Craniofac Surg 1997; 8: 97-99.

13. Montag, M., Morales, L., Dane, S.: Bioabsorbibles: Their use in Pediatric Craniofacial Surgery. J Craniofac Surg 1997; 8: 100-102.

14. Muñoz, M.J., Esparza, J., Hinojosa, J., Salván, R., Romance, A., Muñoz, A.: Fronto-orbital remodeling without orbito-naso-frontal bandeau. Childs Nerv Syst 2003; 19: 353358.

15. Pensler, J.M.: Role of resorbable plates and screws in craniofacial surgery. J Craniofac Surg 1997; 2: 129-134.

16. Pietrzak, W.S., Sarver, D.R., Verstynen, M.L.: Biodegradable Polymer science for the practicing surgeon. J Craniofac Surg 1997; 2: 87-91.

17. Serlos, W., Ashammakhi, N., Törmälä, P., Waris, T.: A new technique for correction of trigonocephaly in an infant: application of an absorbable endocranial plate. Child Nerv Syst 2000; 16: 595-597.

Muñoz-Casado, M.J.; Romance, A.I.; García-Recuero, J.I.: Bioabsorbable osteofixation devices in craniosynostosis. Clinical experience in 216 cases. Neurocirugía 2009; 20: 255-261.

Correspondencia postal: María Jesús Muñoz Casado. Servicio de Neurocirugía Pediátrica. Hospital Universitario 12 de Octubre. Avenida de Córdoba s/n. 28041 Madrid 